\title{
Perancangan Antarmuka Sistem Pelaporan Kerusakan Gedung Menggunakan Metode Human Centered Design (HCD) Berbasis Mobile dengan Teknologi Hybrid (Studi Kasus : Kampus Notohamidjojo FTI-UKSW)
}

\author{
Hendri Suryo Prakoso ${ }^{1}$, Kristoko Dwi Hartomo ${ }^{2}$ \\ ${ }^{1}$ Universitas Kristen Satya Wacana \\ 672016053@student.uksw.edu \\ ${ }^{2}$ Universitas Kristen Satya Wacana \\ kristoko@uksw.edu
}

\section{ARTICLE INFO}

Article history:

Received 12 February 2020

Received in revised form 14 April 2020

Accepted 02 May 2020

Available online 31 July 2020
ABSTRACT

The information system has become a media that has been implemented in the current era in various fields. One of them is the building damage system where the system is intended to facilitate the passing of damage information and efficiencies when making documentation of damage that has occurred. This problem is raised in this design with a case study on a campus that is the Notohamidjojo campus of Satya Wacana Christian University Faculty of Information Technology. With the development of advanced technology and many platforms that can be made to do system damage management. This design is focused on creating a user-friendly system interface design. The design is implemented to implement the method of Human Centered Design (HCD) because using this method can produce interfaces that suit the needs of the system users. This design also uses the technology of Hybrid which by using the technology this system can run on Android and iOS. The testing of the interface is done using the End User Computing Satisfaction (EUCS) method by getting more than 90.0 results indicating that the design of the damage reporting system using HCD and EUCS methods is valid and able to making a design interface system reporting malfunction.

Keywords : HCD, EUCS, interface, reporting, malfunction

\section{Pendahuluan}

Kerusakan saat ini sudah terjadi di banyak hal seperti infrastruktur gedung, jalan dan kerusakan yang terjadi pada alam. Salah satu contoh adalah kerusakan jalan tol, para pekerja kesulitan untuk mengetahui hal tersebut sehingga para pekerja ini membuat sistem yang dapat melakukan pelaporan kerusakan jalan yang terjadi pada kilometer tertentu sehingga petugas pun 
lebih mudah melakukan penanganan kerusakan dengan cepat. Hal inilah yang menjadi alasan perancangan sistem ini dibuat.

Kampus Notohamidjojo adalah gedung yang ditempati oleh Fakultas Teknologi Informasi UKSW yang berada di blotongan salatiga. Gedung ini kurang lebih sudah pakai selama 4 tahun akan tetapi kondisinya banyak yang rusak baik dari infrastruktur, fasilitas laboratorium komputer dan peralatan furnitur. Dari kerusakan tersebut yang menangani adalah pihak sarana dan prasarana fakultas, dengan terlalu banyaknya kerusakan yang ada pihak sarana dan prasarana memiliki kesulitan untuk mengetahui, menangani dan mengelola kerusakan yang terjadi. Kesulitan tersebut didapatkan karena pelaporan kerusakan masih dilakukan secara lisan begitu juga dari pihak sarana dan prasarana juga kesulitan untuk membuat laporan kerusakan yang nantinya akan dikirim ke bagian biro manajemen kampus (BMK). Maka dari itu diperlukan sistem untuk menunjang proses pelaporan kerusakan tersebut. Untuk membuat sebuah tampilan yang dapat memberikan informasi yang lebih jelas sistem ini dirancang menggunakan metode human centered design (HCD) karena metode ini memiliki kaidah yang sesuai dengan kebutuhan, kebiasaan dan kapabilitas dari pengguna aplikasi [1],[12].

Perkembangan teknologi informasi yang semakin maju ini banyak menawarkan inovasi yang bertujuan untuk memberikan kemudahan terhadap penggunanya. Banyak hasil perkembangan teknologi sebagai bukti yang luar biasa seperti smartphone Android yang sekarang sudah menjadi kebutuhan umum kemudian website yang sekarang juga sudah dibutuhkan dengan kegunaan untuk manajemen, promosi, e-commerce dll. Kedua platform inilah yang akan digunakan dalam sistem ini [2],[3].

Perancangan sistem ini dapat menggunakan berbagai macam metode, salah satunya dengan menggunakan metode human centered design (HCD). Peracangan ini difokuskan pada bagian antarmuka (user interface) dengan menerapkan kaidah-kaidah yang ada dalam metode HCD. Metode ini digunakan untuk mendapatkan hasil antarmuka yang memenuhi kebutuhan pengguna. Prinsip dari metode ini yaitu mudah dikenali, konsisten, operasi yang sesuai dengan prediksi, mudah dalam menjalankan sistem. Perancangan ini juga menggunakan teknologi hybrid pada platform smartphone (mobile) agar sistem atau aplikasi dapat berjalan secara cross platform [2].

\subsection{Tinjauan Pustaka}

Penelitian dengan judul Perancangan Antarmuka Web Access Dwelling Time menggunakan Metode Human Centered Design pada Kantor Pengawasan dan Pelayanan Bea Cukai Tipe Madya Pabean (TMP) Tanjung Perak Kota. Pada penelitian tersebut menjelaskan bahwa metode yang digunakan mampu membangun sebuah sistem dengan antarmuka yang sesuai dengan keinginan pengguna yaitu KPPBC TMP Tanjung Perak. Peneliti juga memberikan saran untuk melakukan penelitian dengan metode yang lain seperti metode RUP, karena beberapa fitur tidak dapat berjalan secara maksimal jika menggunakan metode HCD [2].

Perancangan Aplikasi Android Hybrid Untuk Pemilihan Lokasi Kuliner. Pada proses perancangan tersebut menggunakan metode Simple Additive Weighting (SAW), Sistem Informasi Geografis (GIS) dan menggunakan Framework PhoneGap. Hasil dari perancangan tersebut adalah dapat menampilkan 5 opsi tuma makan terbaik melalui visualisasi peta dari Google Maps dan Google Maps juga berperan dalam melakukan perhitungan jarak dan waktu [8].

Penelitian Evaluasi dan Perancangan User Interface Untuk Meningkatkan User Experience Menggunakan Metode Human Centered Design dan Heuristic Evaluation pada Aplikasi Ezypay. Hasil dari penelitian tersebut adalah analisis masalah dan memberikan

TRANSFORMATIKA Vol. 18, No. 1, July 2020: 1-12 
rekomendasi kepada pengembang dengan tepat untuk melakukan perbaikan selanjutnya serta prototype sebagai gambaran dari solusi [3].

Berdasarkan penelitian sebelumnya metode Human Centered Design dan juga teknologi Hybrid Android telah banyak dilakukan (relevan) pada berbagai penelitian dengan diimplementasikan pada pembahasan yang berbeda, baik itu berbeda secara metode, implementasi (platform) dan studi kasus. Maka pada penelitian ini akan membahas tentang Aplikasi pelaporan kerusakan gedung FTI UKSW (Kampus Notohamidjojo) dengan menggunakan metode Human Centered Design (HCD) dengan teknologi Hybrid Android yang dimana nanti juga dapat dikembangkan untuk pelaporan kerusakan pada hal yang lain [4].

\section{Metode Penelitian}

2.1 Tahapan penelitian ini dilakukan menggunakan model pengembangan perangkat lunak sekuensial linier, sebagai berikut :

a) Tahap pertama Identifikasi Masalah

Tahap ini menentukan masalah dan solusi apa saja yang akan dibahas pada penelitian ini. Permasalahan yang didapatkan pada pembahasan ini adalah membuat desain sistem dalam bentuk prototype. Kemudian pada tahap ini juga diberikan solusi untuk membuat sistem pelaporan kerusakan dengan antarmuka yang mudah untuk dipahami dan dipakai [11], [9].

b) Tahap kedua Studi Literatur

Tahap ini menentukan studi kasus dan batasan batasan yang lakukan oleh sistem. Hal ini dilakukan secara wawancara dengan supervisor dari sarana dan prasarana fakultas. Tahapan ini juga menentukan akan metode yang akan digunakan yaitu metode Human Centered Design (HCD), dimana dengan metode ini tampilan antarmuka dapat berfokus pada kebutuhan dari pengguna sehingga sistem akan lebih mudah untuk digunakan dan dipahami.

c) Tahap ketiga Analisis Metode

Tahap ini proses menentukan metode dan teknologi yang akan diterapkan untuk melakukan perancangan. Hasil dari tahap ini adalah menggunakan metode Human Centered Design karena dengan metode ini berfokus dengan orang yang akan menggunakan sistem ini dan sesuai dengan siklus dari HCD sendiri yaitu selalu melakukan evaluasi di setiap prototype yang telah dibuat [8], [9].

d) Tahap keempat Prototype

Tahap ini adalah proses untuk melakukan pembuatan prototype sistem pelaporan kerusakan dengan menerapkan kaidah-kaidah dari metode HCD beserta dengan siklus yang ada di dalam metode.

e) Tahapan Rilis Aplikasi

Tahap ini melakukan demo hasil dari desain prototype yang telah dikerjakan dan juga melakukan proses pengujian terhadap desain yang telah dibuat.

f) Tahapan laporan

Tahap ini menjelaskan tentang desain sistem yang telah dikerjakan kedalam bentuk UML Unified Model Language.

2.2 Prosedur perancangan yang dilakukan yaitu membuat desain sistem menggunakan UML Unified Model Language dan membuat desain interface dalam bentuk prototype :

a) Proses untuk menentukan pengguna sistem

b) Proses pembuatan use case, class diagram dan activity diagram

c) Proses pembuatan desain user interface

d) Proses melakukan evaluasi terhadap user interface yang telah dibuat

e) Proses pengujian dengan metode End User Computing Satisfaction (EUCS) agar mendapatkan feedback dari pengguna mengenai antarmuka sistem yang telah dibuat. Pengujian dilakukan oleh semua pegawai sarana dan prasarana Fakultas Teknologi Informasi UKSW. 


\subsection{Human Centered Design (HCD)}

Metode ini yang diterapkan untuk melakukan proses pembuatan antarmuka sistem. Human Centered Design (HCD) adalah suatu pengembangan sistem yang memiliki tujuan untuk membuat sistem lebih interaktif dan bermanfaat terhadap pengguna sistem. HCD memiliki 4 siklus, yang pertama memahami dan menentukan konteks penggunaan, menspesifikasi persyaratan pengguna, membuat desain solusi dan melakukan evaluasi desain. Dengan menggunakan metode ini juga dapat mengurangi desain antarmuka yang membuat pengguna sulit untuk memahami dalam penggunaan sistem. Maka dari itu sistem ini menggunakan metode HCD dengan berfokus pada manusia yang nantinya akan menggunakan sistem ini [5-7].

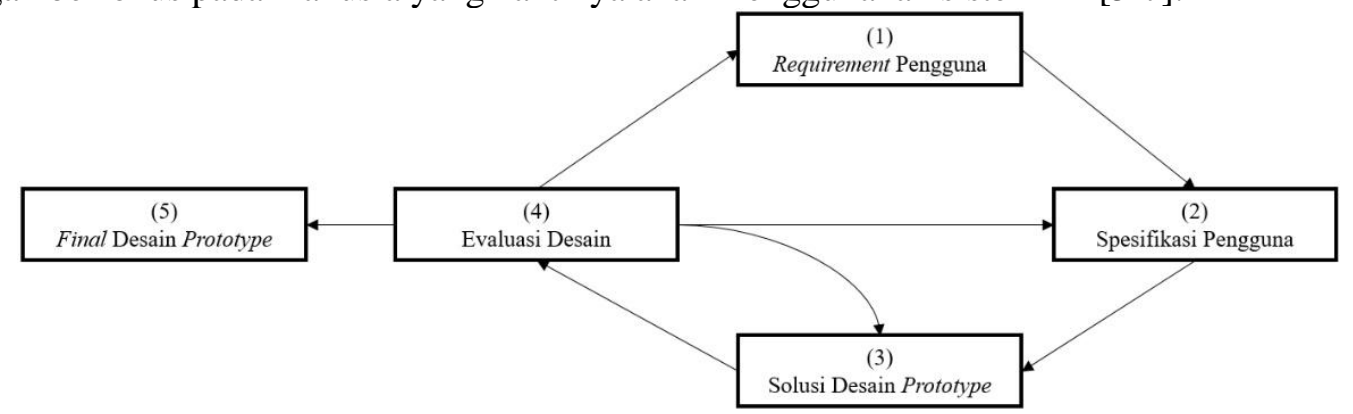

Gambar 1. Siklus Metode Human Centered Design (HCD)[5]

Spesifikasi untuk desain antarmuka sistem yang diinginkan, pada mobile dapat melakukan preview gambar kerusakan dan desain di buat seminimalis mungkin agar lebih mudah untuk dipahami. Kemudian juga membuat desain untuk melakukan proses pengelolaan untuk melakukan manajemen kerusakan dalam bentuk website. Website ini didesain dengan teknik flat design yang dimana hanya menggunakan satu warna pokok yaitu warna biru dengan penambahan icon di beberapa navigasi seperti add dan search beserta dengan warna yang kontras sehingga pengguna lebih mudah untuk memahami ketika menggunakan sistem. Proses ini dilakukan sesuai dengan siklus dari HCD yaitu membuat desain dan melakukan evaluasi oleh pengguna dan proses yang dilakukan sebanyak dua kali sehingga menghasilkan 2 prototype yang memiliki perbedaan untuk pengembangan desain antar sistem (Tabel 1).

\subsection{Teknologi Hybrid}

Teknologi Hybrid adalah aplikasi yang dapat berjalan pada platform yang berbeda dan juga aplikasi ini merupakan gabungan dari aplikasi native dan web. Aplikasi ini dibangun menggunakan bahasa pemrograman web yang didesain agar dapat dijalankan diberbagai device seluler. Dengan adanya teknologi ini maka akan memperingan bagi developer untuk melakukan proses pengambangan aplikasi dalam jenis smartphone [8], [9].

\section{Hasil dan Pembahasan}

\subsection{Perancangan}

\subsubsection{Use Case Diagram}

Gambar 2 menjelaskan tentang pengguna menggunakan sistem. Terdapat 5 user yang terdiri dari superuser, admin, supervisor, pegawai (pegawai sarana dan prasarana) dan mahasiswa. Masing-masing user memiliki fungsi tersendiri seperti superuser memiliki hak akses full control terhadap segala kerusakan, pengelolaan history kerusakan dan pengelolaan user. Kemudian admin disini hanya dapat melakukan pengelolaan kerusakan dan user dengan batasan tidak dapat menghapus data yang ada. Supervisor dan pegawai dapat melakukan melaporkan

TRANSFORMATIKA Vol. 18, No. 1, July 2020: 1-12 
kerusakan, melakukan eksekusi (perbaikan) kerusakan dan dapat melihat daftar kerusakan yang telah dikerjakan dan yang sedang dikerjakan yang perbedaannya terdapat pada user supervisor dapat melakukan penugasan kepada user pegawai. Kemudian mahasiswa hanya dapat melakukan proses pelaporan kerusakan saja dan melakukan pengelolaan profile user.

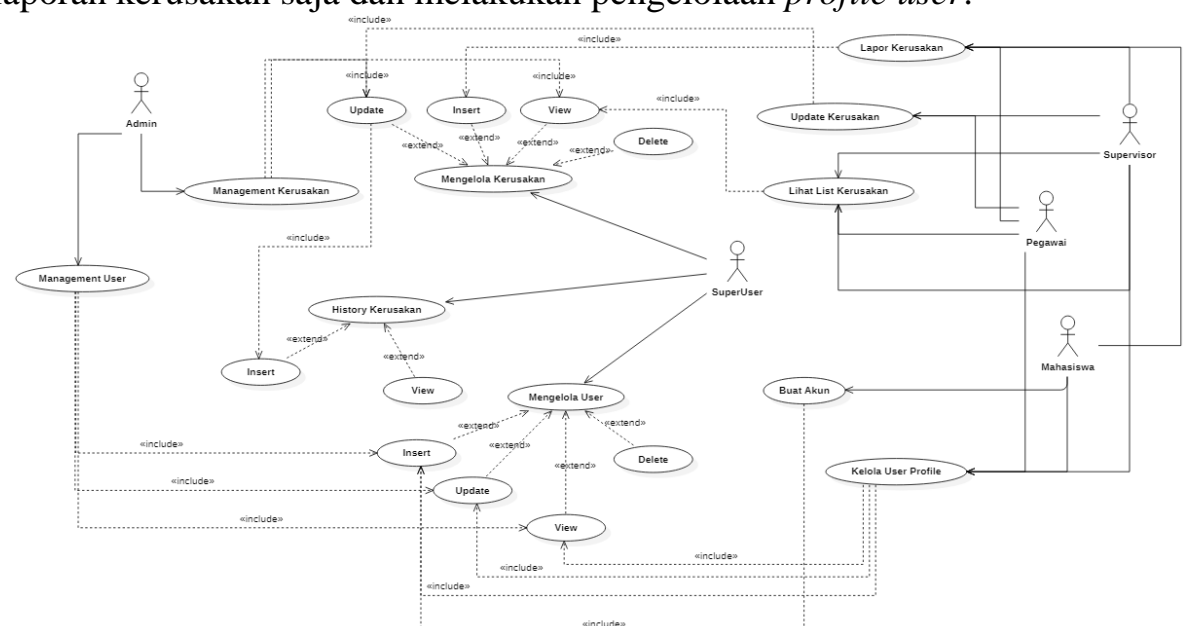

Gambar 2. Use Case Diagram Sistem pelaporan Kerusakan

\subsubsection{Class Diagram}

Gambar 3 memaparkan class diagram, terdapat 3 entitas utama yakni kerusakan, user dan history kerusakan beberapa attribut diberikan input secara otomatis melalui sistem seperti tanggal, user id dan id kerusakan hal tersebut bertujuan untuk error handling. Setiap entitas saling terhubung dengan controller untuk melakukan proses insert, update dan delete.

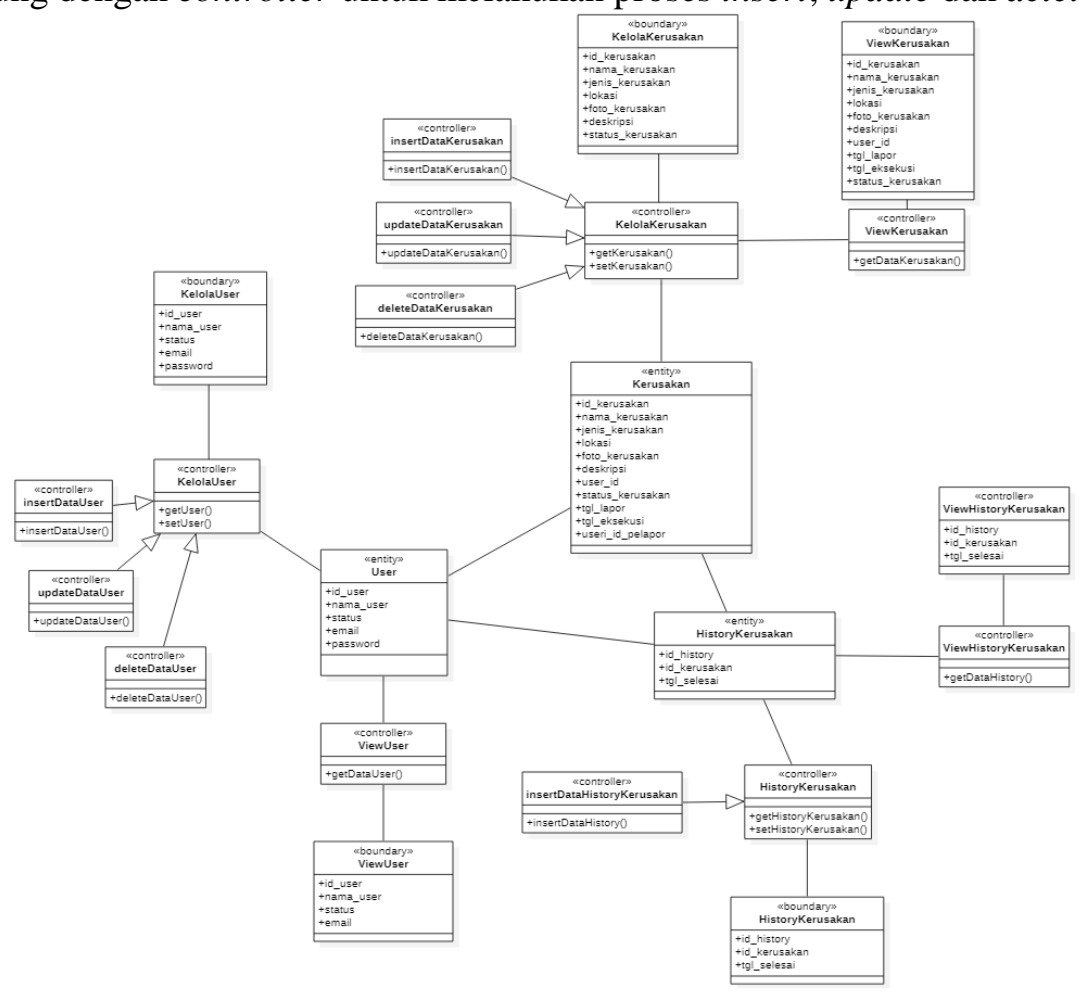

Gambar 3. Class Diagram Sistem Pelaporan Kerusakan

\subsection{Prototype}

Skenario pada sistem ini adalah user (mahasiswa) melakukan pelaporan kerusakan dengan mengisikan form yang telah disediakan, kemudian data tersebut akan dikirimkan oleh sistem ke database dan mengirimkan pesan bahwa ada laporan kerusakan baru kepada user 
supervisor. Data tersebut berisikan nama kerusakan, jenis kerusakan, lokasi, foto dan deskripsi kerusakan. Setelah itu jika supervisor telah melakukan konfirmasi maka supervisor lah yang akan melakukan perbaikan, jika supervisor memilih untuk melakukan penugasan maka sistem akan mengirimkan pesan penugasan terhadap user pegawai untuk melakukan proses perbaikan dan melakukan update kerusakan yang telah ditugaskan.

Desain antarmuka sistem ini menggunakan teknik flat design dan menggunakan pemilihan warna yang melambangkan dari Fakultas Teknologi Informasi yaitu warna biru dan putih. Tujuan pemilihan warna ini digunakan untuk terlihat lebih kontras sehingga user tidak kebingungan ketika menggunakan sistem ini. Pada antarmuka juga diberikannya navigasi agar user juga lebih mudah untuk memahaminya. Prototype ini merupakan desain yang telah sesuai dengan kebutuhan dari pengguna dan telah melakukan proses sesuai dengan siklus HCD. Antarmuka sistem baik dari mobile yang digunakan untuk proses pelaporan dan perbaikan kerusakan sedangkan website digunakan untuk melakukan pengelolaan kerusakan. Dalam proses desain antarmuka juga menerapkan kaidah dari metode HCD sendiri yaitu konsistensi dari layout atau konten dan menambahkan icon beserta keterangan text agar user lebih mudah untuk memahami antarmuka dari sistem.

\subsubsection{Mobile}

a) Gambar 5, menunjukan tampilan dari form untuk melakukan pelaporan kerusakan. Pengguna juga dapat melihat preview gambar dan juga tidak terlalu banyak form yang harus diisi karena pada tampilan ini menerapkan kaidah dari metode HCD yaitu dengan menampilkan sesuai dengan kebutuhan dari pengguna. Tampilan ini juga diberikannya navigasi dalam bentuk icon dan text agar lebih mudah untuk dipahami pengguna.

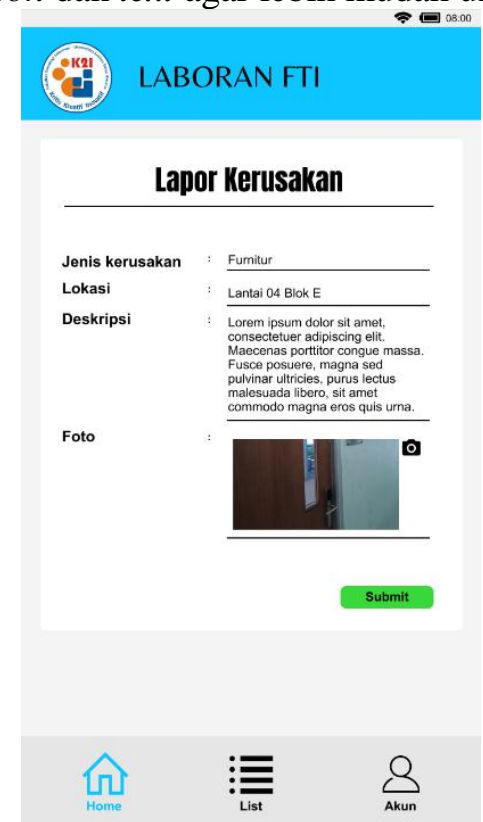

Gambar 5. Tampilan Laporkan Kerusakan

b) Tampilan Penugasan Pegawai

Gambar 6 dan 7, menunjukan ketika user supervisor ingin melakukan konfirmasi kerusakan untuk langsung diperbaiki atau ingin melakukan penugasan ke user pegawai agar kerusakan segera diperbaiki. 


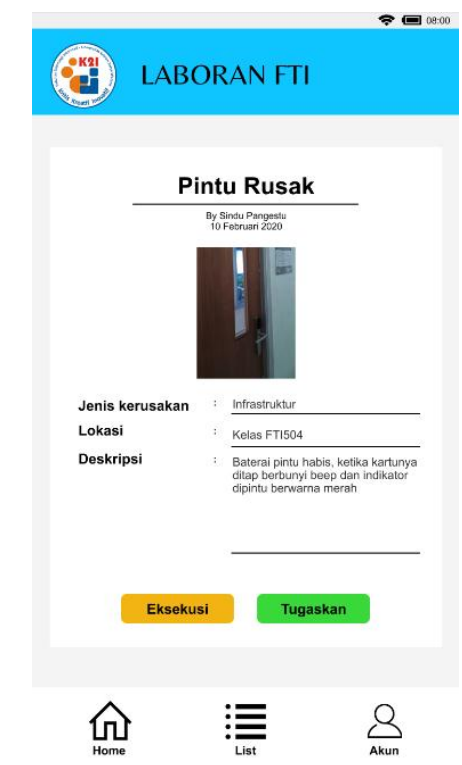

Gambar 6. Tampilan Preview Konfirmasi atau diTugaskan

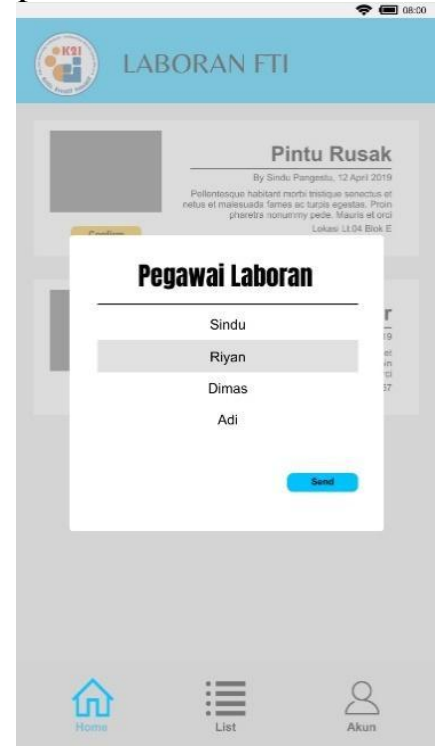

Gambar 7. Tampilan Daftar Pegawai dari Sarana dan Prasarana Fakultas

c) Tampilan Eksekusi Kerusakan

Gambar 8, menunjukan ketika user supervisor dan pegawai melakukan update kerusakan setelah kerusakan sudah diperbaiki dan mengirimkan foto terbaru. Pada tahapan ini sistem juga akan melakukan proses update status done kerusakan yang ada di database. Ketika melakukan update kerusakan atau sudah melakukan perbaikan, tampilan juga menerapkan kaidah dari metode HCD kebiasaan dari pengguna yaitu di dalam memberikan keterangan dan juga mengirimkan kondisi kerusakan dalam bentuk foto. 


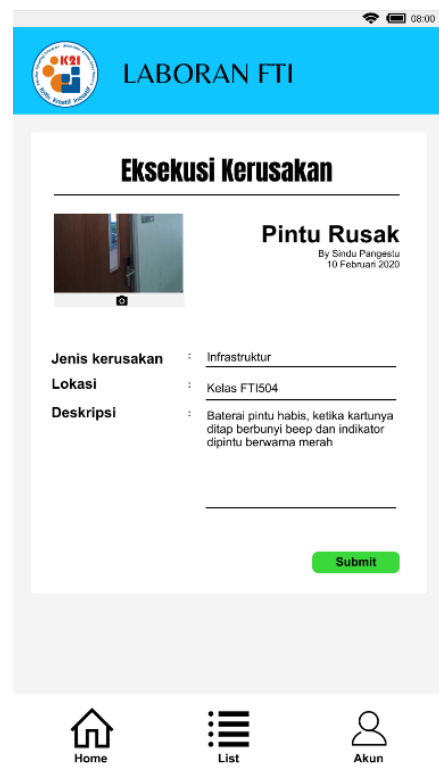

Gambar 8. Tampilan Eksekusi Kerusakan

d) Tampilan Daftar Kerusakan

Gambar 9, menjelaskan untuk daftar kerusakan yang telah dikerjakan dengan status "done". Sedang dikerjakan "On Process" dan waiting untuk menunggu konfirmasi atau penugasan perbaikan kerusakan. Hal tersebut diberikan sebagai navigasi untuk pengguna dan juga karena pengguna juga sudah terbiasa dengan tampilan keterangan jejak untuk menyelesaikan kerusakan.

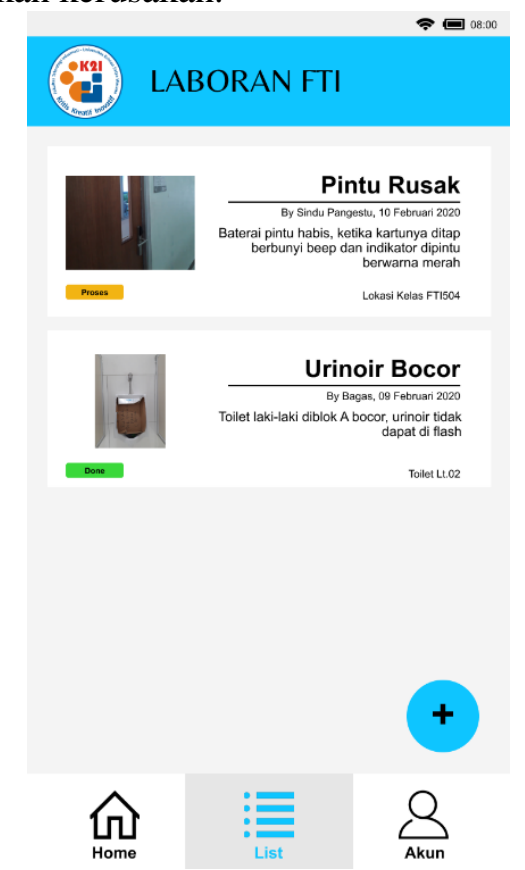

Gambar 9. Tampilan Daftar Kerusakan

TRANSFORMATIKA Vol. 18, No. 1, July 2020: 1-12 


\subsubsection{Website}

Prototype website ini yang nantinya akan dioperasi oleh user superuser dan admin untuk melakukan pengelolaan terhadap kerusakan. Di Dalam website ini user dapat melakukan proses pengelolaan sesuai dengan kebutuhan seperti insert, update, delete dan view.

a) Admin

Gambar 1, menunjukan tampilan utama dari user superuser dan admin adalah kedalam bentuk grafik dengan jumlah kerusakan setiap jenis kerusakan yaitu furniture, infrastruktur, electronic dan others.

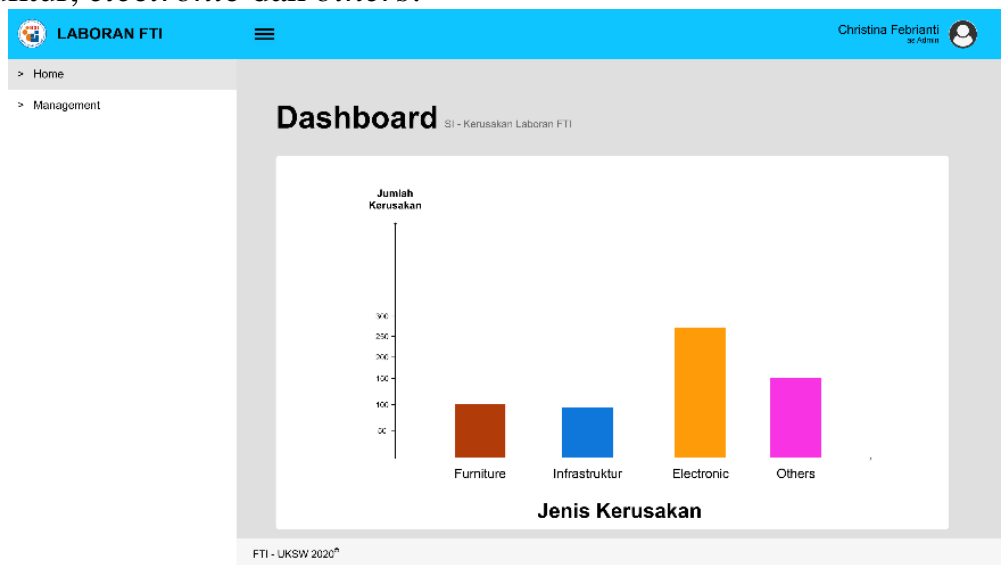

Gambar 10. Tampilan Dashboard Admin

Gambar 11 dan 12, menunjukan tampilan ketika melakukan manajemen kerusakan dan manajemen user. Untuk user admin dibatasi dengan tidak dapat menghapus kerusakan akan tetapi pada user superuser dapat menghapus data kerusakan.

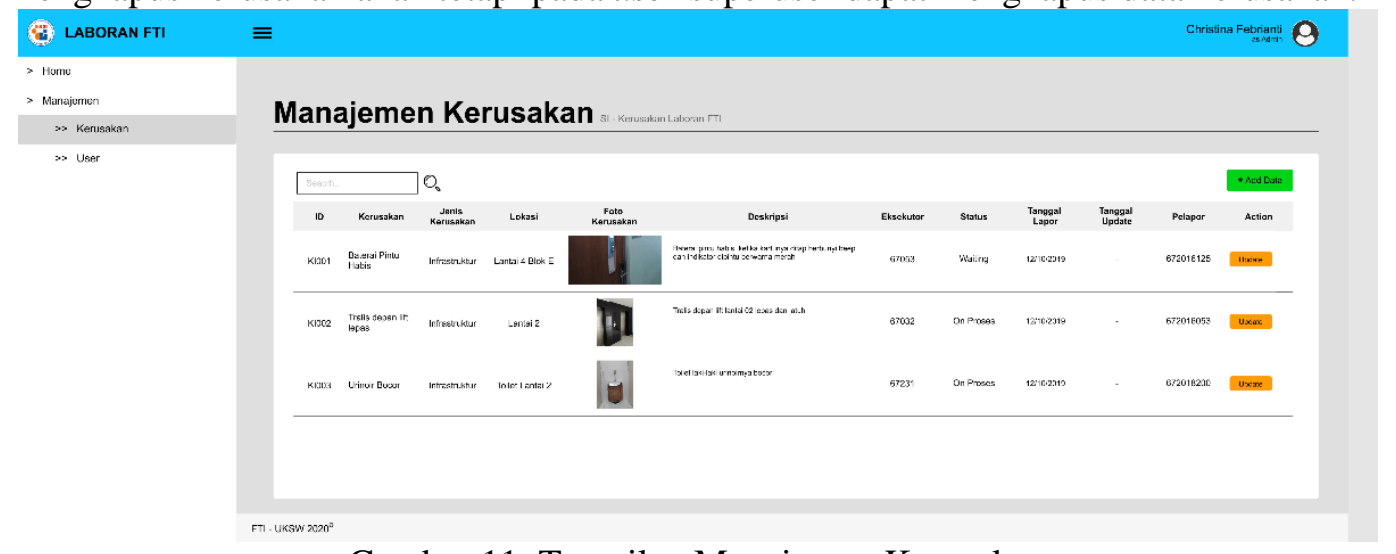

Gambar 11. Tampilan Manajemen Kerusakan 


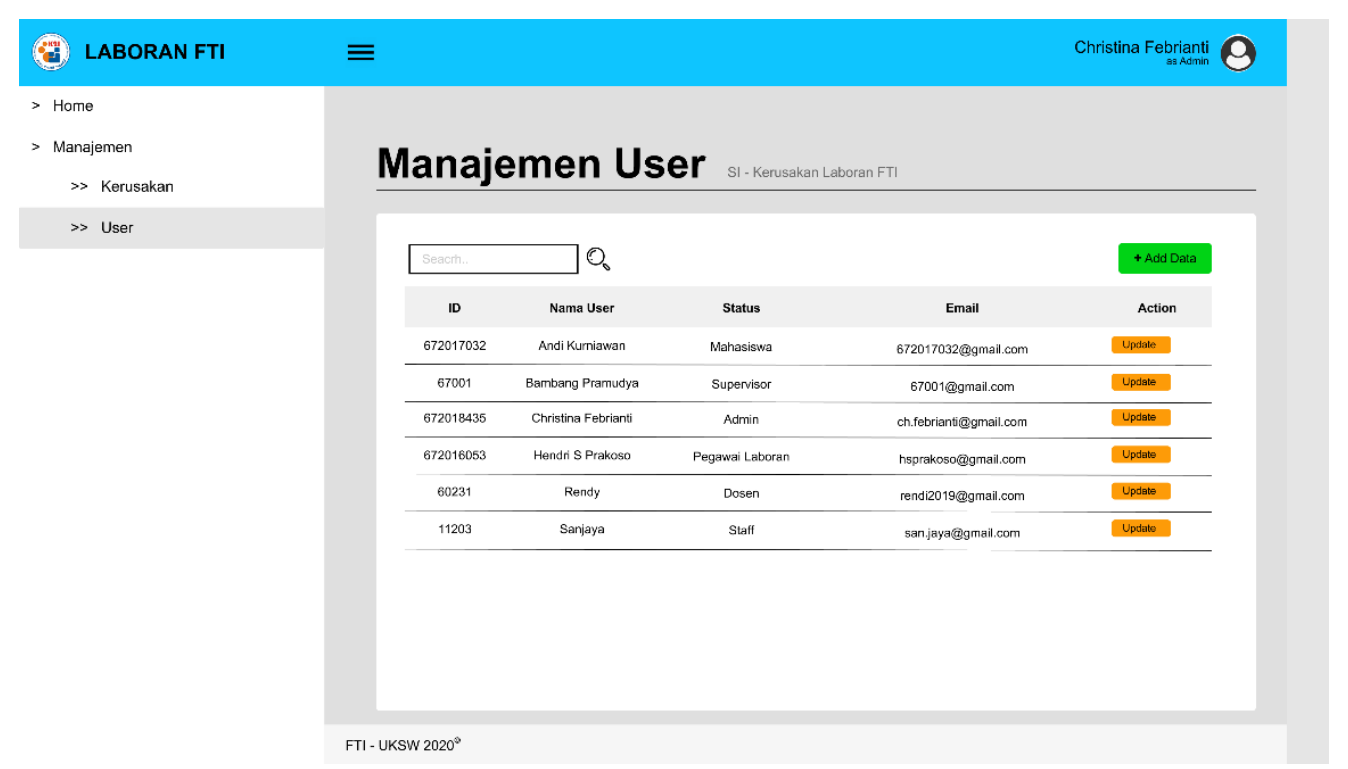

Gambar 12. Tampilan Manajemen User

b) Superuser

Gambar 13, menampilkan tampilan history kerusakan secara jelas mulai dari jenis kerusakan, tanggal pelaporan hingga tanggal selesai beserta dengan jejak dari yang melakukan perbaikan kerusakan. Kaidah dari metode HCD yang diterapkan pada tampilan ini ada menampilkan informasi yang dibutuhkan oleh pengguna sistem.

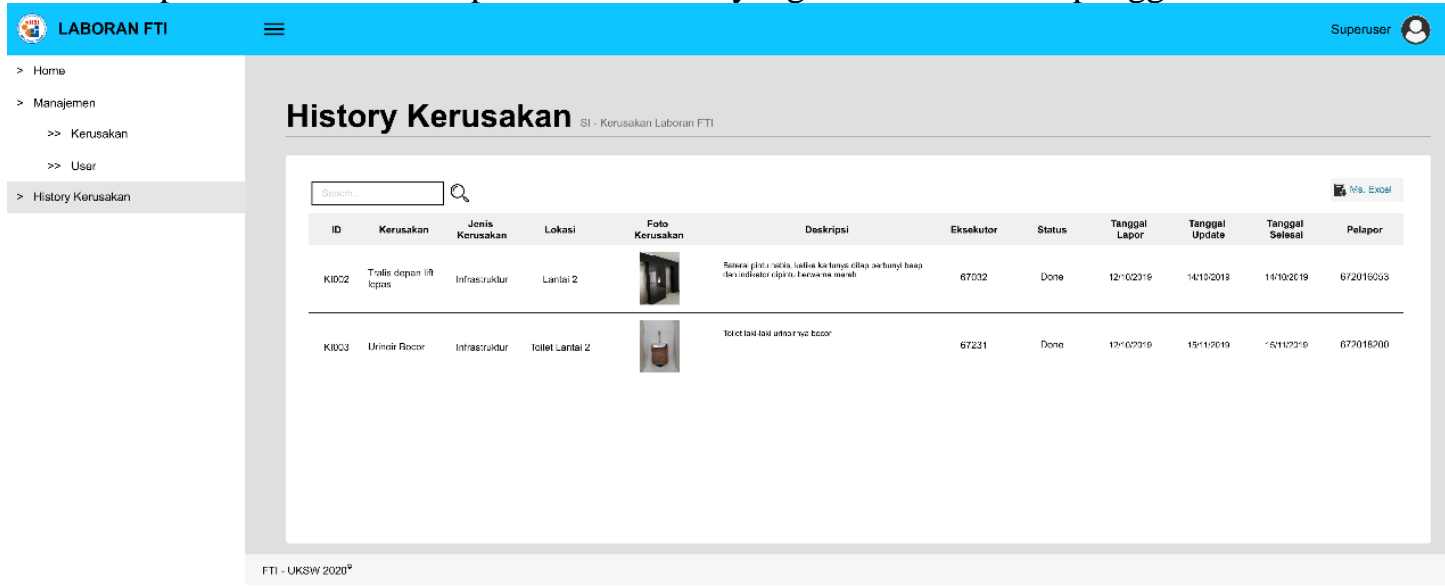

Gambar 13. Tampilan History Kerusakan

3.2.3 Hasil Kesesuaian Desain dengan Pengguna

Hasil kesesuaian dari spesifikasi desain pengguna dengan menerapkan metode HCD beserta dengan siklus yang ada di dalam metode ditunjukan sebagai berikut :

TRANSFORMATIKA Vol. 18, No. 1, July 2020: 1-12 
Table 1. Revisi User Interface Sistem Pelaporan Kerusakan

\begin{tabular}{clccc}
\hline No. & \multicolumn{1}{c}{ Spesifikasi } & Prototype 1 & Prototype 2 \\
\hline 1 & $\begin{array}{l}\text { Pada dashboard ditampilkan dalam } \\
\text { bentuk grafik kerusakan dan list } \\
\text { kerusakan. }\end{array}$ & $\begin{array}{c}\text { Kurang grafik } \\
\text { kerusakan }\end{array}$ & $\begin{array}{c}\text { Dihilangkan, } \\
\text { dipindah ke Web }\end{array}$ \\
\hline 2 & $\begin{array}{l}\text { Diberikannya identitas dari instansi } \\
\text { icon } \text { dan warna) }\end{array}$ & Belum & Sudah \\
\hline 3 & Layout yang lebih rapi & Belum & Sudah \\
\hline 4 & Preview foto kerusakan & Belum & Sudah \\
\hline 5 & Tampilan user friendly & Belum & Sudah \\
\hline 6 & $\begin{array}{l}\text { Tampilan website user admin dan } \\
\text { superuser }\end{array}$ & Belum & Sudah \\
\hline 7 & Navigasi & Belum & Sudah \\
\hline
\end{tabular}

\subsubsection{Pengujian End User Computing Satisfaction (EUCS)}

Perancangan ini melakukan pengujian menggunakan metode End User Computing Satisfaction. Pengujian ini dilakukan dengan cara kuesioner yang diberikan kepada user yang ada di sarana dan prasarana fakultas. Nilai setiap pertanyaan bernilai berkisar antara $1-4$ dan pertanyaan yang diberikan bagaimana dengan tampilan dari sistem yang telah dibuat. Untuk perhitungan skor dengan cara jumlah total skor dikalikan 100 kemudian dibagi 16 dengan nilai keseluruhan pertanyaan. Nilai EUCS memiliki skala mulai 1 - 100 dengan jumlah minimal responden 5. Perancangan ini diuji dengan jumlah responden 10 sesuai dengan jumlah dari tenaga kerja sarana prasarana Fakultas Teknologi Informasi. Berikut ini adalah hasil dari pengujian dari perancangan sistem ini :

Table 2. Hasil Pengujian Metode EUCS

\begin{tabular}{|c|c|c|c|c|c|c|}
\hline \multirow[t]{2}{*}{ Responden } & \multicolumn{4}{|c|}{ Skor } & \multirow[t]{2}{*}{ Total } & \multirow[t]{2}{*}{ Skor } \\
\hline & 1 & 2 & 3 & 4 & & \\
\hline 1 & 4 & 3 & 3 & 3 & 13 & 81.5 \\
\hline 2 & 4 & 4 & 3 & 4 & 15 & 93.7 \\
\hline 3 & 3 & 4 & 4 & 3 & 14 & 87.5 \\
\hline 4 & 4 & 4 & 3 & 3 & 14 & 87.5 \\
\hline 5 & 4 & 4 & 4 & 4 & 16 & 100 \\
\hline 6 & 4 & 3 & 4 & 4 & 15 & 93.7 \\
\hline 7 & 4 & 3 & 3 & 3 & 13 & 81.2 \\
\hline 8 & 3 & 3 & 4 & 4 & 14 & 87.5 \\
\hline 9 & 4 & 4 & 4 & 4 & 16 & 100 \\
\hline 10 & 4 & 3 & 4 & 4 & 14 & 93.7 \\
\hline \multicolumn{6}{|c|}{ Total Skor } & 906.2 \\
\hline \multicolumn{6}{|c|}{ Rata - rata } & 90.6 \\
\hline
\end{tabular}

Pertanyaan pertama yang diberikan mengacu kepada user interface yang telah dibuat melalui prototype apakah sudah mudah untuk dipahami (user friendly) dalam menggunakan aplikasi ini. Pertanyaan kedua mengarah kepada konten atau layout yang disediakan sudah memenuhi dengan kebutuhan user atau belum. Pertanyaan ketiga mengacu ke informasi yang diberikan atau ditampilkan apakah sudah mudah untuk dipahami dari detail kerusakan yang telah dilaporkan dengan menggunakan sistem ini. Pertanyaan keempat mengarah ke navigasi terhadap sistem apakah navigasi yang diberikan sudah sesuai dengan kebutuhan $u$ ser.

Pengujian yang dilakukan dengan menggunakan End User Computing Satisfaction ini mendapatkan hasil $90.6 \%$. Jadi dengan hasil pengujian yang lebih dari 70\% maka rancangan ini dianggap valid dan tampilan yang dibangun sudah memenuhi kebutuhan begitu juga tampilan telah user friendly sehingga pengguna lebih mudah untuk menggunakan sistem pelaporan kerusakan ini. Demikian perancangan aplikasi pelaporan kerusakan gedung menggunakan metode Human Centered Design (HCD) mampu memenuhi kebutuhan yang terdapat dalam sarana dan prasarana fakultas. 


\section{Kesimpulan}

Jadi dari hasil yang telah dilakukan perancangan aplikasi menggunakan metode Human Centered Design (HCD) ini mampu membangun sebuah sistem yang memiliki desain yang interaktif dan juga informatif sehingga membuat user (pengguna) lebih mudah untuk melakukan pengoperasiannya. Hasil pengujian yang didapatkan yaitu $90.6 \%$ yang menunjukan bahwa perancangan ini valid dan mampu untuk memenuhi kebutuhan dari pihak laboran sebagai pengguna sistem ini.

\section{Daftar Pustaka}

[1] E. Metzker and M. Offergeld, "An Interdisciplinary Approach for Successfully Integrating Human-Centered Design Methods into Development Processes Practiced by Industrial Software Development Organizations," pp. 19-33, 2001.

[2] F. Andriani, Y. T. Mursityo, and H. M. Az-zahra, "Perancangan Antarmuka Web Access Dwelling Time Menggunakan Metode Human Centered Design ( HCD ) Pada Kantor Pengawasan dan Pelayanan Bea dan Cukai ( KPPBC) Tipe Madya Pabean ( TMP ) Tanjung Perak Kota Surabaya,” vol. 3, no. 4, pp. 3407-3416, 2019.

[3] D. R. Anggitama, H. Tolle, and H. M. Az-zahra, "Evaluasi Dan Perancangan User Interface Untuk Meningkatkan User Experience Menggunakan Metode Human Centered Design Dan Heuristic Evaluation Pada Aplikasi EzyPay," vol. 2, no. 12, pp. 6152-6159, 2018.

[4] N. Setiyawati and S. Teguh Bowo Kesuwo, "Pembangunan Aplikasi Pelaporan Kecelakaan Lalu Lintas Berbasis Web Menggunakan Framework Laravel," Assoc. Inf. Syst. - Indones., vol. 2, no. 22, pp. 1-10, 2017.

[5] R. Irwandana, A. D. Herlambang, and M. C. Saputra, "Evaluasi dan Perbaikan Rancangan Antarmuka Pengguna Situs Web Eventmalang Menggunakan Pendekatan Human Centered Design,” vol. 3, no. 2, pp. 1334-1341, 2019.

[6] D. A. Norman, "Human-centered design considered harmful," Interactions, vol. 12, no. 4, p. 14, 2005.

[7] R. Harte et al., "A Human-Centered Design Methodology to Enhance the Usability, Human Factors, and User Experience of Connected Health Systems: A Three-Phase Methodology," JMIR Hum. Factors, vol. 4, no. 1, p. e8, 2017.

[8] V. N. Firdausy, F. Agus, and I. F. Astuti, “Aplikasi Android Hybrid Untuk Pemilihan Lokasi Kuliner," Inform. Mulawarman J. Ilm. Ilmu Komput., vol. 12, no. 1, p. 30, 2018.

[9] S. Alfeno and W. I. Tiana, "Aplikasi Mobile Commerce Berbasis Android Pada Distro," vol. 4, no. 2, pp. 169179.

[10] C. Putnam, E. Rose, E. J. Johnson, and B. Kolko, “Adapting User-Centered Design Methods to Design for Diverse Populations,” Inf. Technol. Int. Dev., vol. 5, no. 4, pp. 51-74, 2009.

[11] Handhoko. 2020. Wawancara Supervisor di-Kantor Sarana dan Prasarana, FTI227.

[12] FTIUKSW. 2003. Profil FTI UKSW http://fti.uksw.edu/tentang-fti-uksw/profil-fti-uksw.html (diakses pada tanggal 14 Januari 2020)

TRANSFORMATIKA Vol. 18, No. 1, July $2020: 1-12$ 